\author{
JUSTyNA MUWEIS \\ Katedra Zarzadzania $w$ Energetyce \\ Wydziat Zarzadzania \\ AGH Akademia Górniczo-Hutnicza \\ Gramatyka 10, 30-067 Kraków \\ E-mail: jmuweis@zarz.agh.edu.pl
}

\title{
ODPADY W PRZESTRZENI KOSMICZNEJ I PRÓBY ICH MINIMALIZACJI*
}

\section{WSTEP}

Problematyka odpadów generowanych przez człowieka i ich negatywne oddziaływanie na środowisko ma zasięg wykraczajacy poza obszar naszej planety. Odpady pochodzenia antropogenicznego znajduja się również w przestrzeni kosmicznej, stanowiąc potencjalne zagrożenie dla życia ludzi oraz pozostałych form życia na Ziemi. Odpady poruszajace się po orbitach okołoziemskich sa przede wszystkim niebezpieczne dla innych obiektów przebywających w przestrzeni kosmicznej. Problemem jest wzrastajaca ich liczebność i fakt, że znajduja się one w ciągłym ruchu, rozwijając duże prędkości.

Rozwój nowoczesnych technologii przez ostatnie dziesiątki lat sprawił, iż przestrzeń kosmiczna stawała się coraz bardziej pożądanym obszarem, w konsekwencji czego orbity okołoziemskie sa obecnie zatłoczone przez krażące na nich, pracujace i nieczynne już, satelity oraz inne mniejsze odpady. Zagrożenie stanowia zarówno odpady o niewielkich gabarytach, jak również duże satelity napędzane energia nuklearna, które moga być niebezpieczne przez uwalnianie do atmosfery szkodliwych radioaktywnych substancji. Jedno $z$ potencjalnie największych zagrożeń stanowia jednak kolizje odpadów $z$ innymi obiektami kosmicznymi poruszajacymi się w przestrzeni kosmicznej. Wraz $\mathrm{z}$ rozwojem przemysłu kosmicznego i wzmożonej eksploracji kosmosu problem odpadów kosmicznych staje się coraz bardziej istotny. Obecnie, poszukuje się efektywnych rozwiązań $\mathrm{w}$ celu zminimalizowania ilości tego

typu odpadów oraz niebezpieczeństw jakie moga wywoływać. Rozwiazania te maja wymiar zarówno techniczny, środowiskowy jak i prawny. Problem wymaga kompleksowych rozwiązań związanych $z$ zapobieganiem powstawania odpadów, ich minimalizacja oraz poszukiwaniem metod ich deorbitacji, $z$ jak najmniejszą szkodliwością dla środowiska.

\section{WYKORZYSTYWANIE PRZESTRZENI KOSMICZNEJ PRZEZ CZŁOWIEKA}

Wraz $z$ rozwojem techniki, przestrzeń kosmiczna najbliższa Ziemi zaczęła być coraz bardziej atrakcyjna, a umieszczane na niej obiekty dawały coraz większe możliwości prowadzenia bardziej dokładnych badań kosmosu, niż z powierzchni naszej planety.

Pierwsze badania teoretyczne dotyczace możliwości lotów kosmicznych rozpoczęto w XIX w. Rozważania te dotyczyły najpierw możliwości wyrzucenia $\mathrm{w}$ przestrzeń pozaziemska ciała, które mogłoby stać się satelita Ziemi. Warunkiem tego było nadanie ciału prędkości większej od $7,91 \mathrm{~km} / \mathrm{s}$, w kierunku równoległym do powierzchni Ziemi, aby mogło obiegać Ziemię. Tę prędkość konieczna do zrównania siły ciążenia ku środkowi Ziemi, nazywamy pierwszą prędkościa kosmiczna (RYBKA 1978). Do prowadzenia badań w przestrzeni kosmicznej niezbędne więc były, i nadal sa, sztuczne satelity. Sa to obiekty załogowe lub bezzałogowe, krażące wokół ciała niebieskiego po orbicie zamkniętej. Sztuczny satelita wykonuje ruch obejmujacy: start, lot orbitalny, ewentualnie kontrolowaną deorbitację. Początkowo,
\end{abstract}

Slowa kluczowe: deorbitacja, odpady kosmiczne, ryzyko kolizji, sztuczne satelity

*Wydanie artykułu finansowane przez Akademię Górniczo-Hutniczą im. Stanisława Staszica w Krakowie (dotacja podmiotowa na utrzymanie potencjału badawczego). 
sztuczne satelity umieszczane były na orbitach, których perygeum przebiegało nisko nad Ziemia, co wiązało się $z$ ich szyblim wejściem w atmosferę. Przyjęto, że maksymalna odległość, przy której atmosfera Ziemi jeszcze minimalnie może wpływać na ruch orbitalny satelity to ok. 1000-1500 km.

Pierwszy taki obiekt, o nazwie Sputnik 1, został wystrzelony 4 października 1957 r. Kolejny, Sputnik 2, został wysłany na wysokość $1700 \mathrm{~km}$ od powierzchni Ziemi 3 listopada 1957 r. Było to apogeum (maksymalna odległość od powierzchni Ziemi), zaś minimalna odległość wynosiła ok. $200 \mathrm{~km}$.

Po sukcesach w eksploracji kosmosu, w latach 60. XX w. coraz większe znaczenie zaczęły mieć satelity wykorzystywane w różnych celach. Satelity meteorologiczne służa do pomiarów właściwości chemicznych i fizycznych powierzchni Ziemi oraz jej atmosfery. Geodezyjne znajduja zastosowanie do celów triangulacyjnych (dotyczących pomiarów osnów geodezyjnych) i pozwalaja na dokładne wyznaczanie odległości międzykontynentalnych oraz powiazanie sieci triangulacyjnych $z$ różnych kontynentów. Umożliwiało to osiągnięcie dokładności rzędu kilku metrów, podczas gdy przed stosowaniem sztucznych satelitów Ziemi, odległości międzykontynentalne znano $z$ dokładnościa najwyżej paruset metrów (RYBKA 1978). Współczesne techniki wykorzystujace satelity geodezyjne i specjalne lasery naziemne osiagaja dokładności rzędu centymetrów. Przykładem jest stacja laserowa w Borowcu pod Poznaniem.

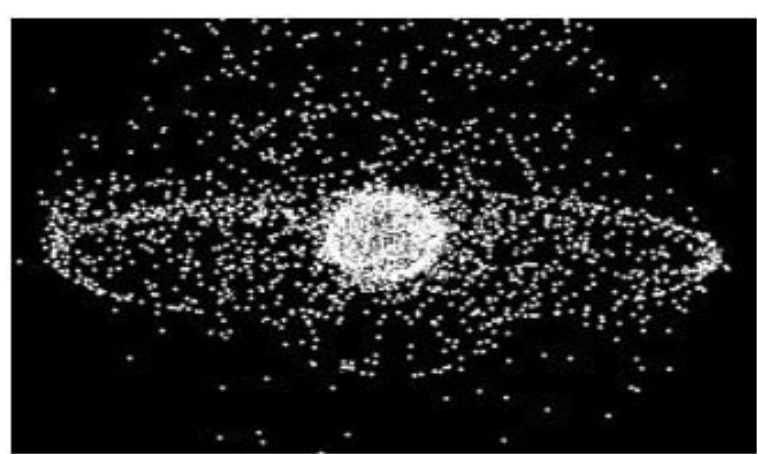

Ryc. 1. Odpady kosmiczne w przestrzeni orbitalnej Ziemi (Źródło: NASA https://www.orbitaldebris.jsc.nasa.gov/photo-gallery.html).

Bardzo popularne satelity telekomunikacyjne służa natomiast do transmitowania sygnałów radiowych i telewizyjnych między stacjami naziemnymi. Satelity wykorzystywane sa również do tworzenia nowoczesnych systemów nawigacji satelitarnej, przydatnych w różnych dziedzinach życia gospodarczego.

\section{CHARAKTERYSTYKA ODPADÓW KOSMICZNYCH}

Obiekty znajdujące się na orbitach wokółziemskich moga być pochodzenia naturalnego (nazywane meteroidami) lub wytworzone przez człowieka. W pracy analizowane sa odpady pochodzace $z$ działalności i aktywności człowieka w przestrzeni kosmicznej. W literaturze przedmiotu najczęściej można

Tabela 1. Klasyfikacja orbit okołoziemskich i występujące na nich obiekty.

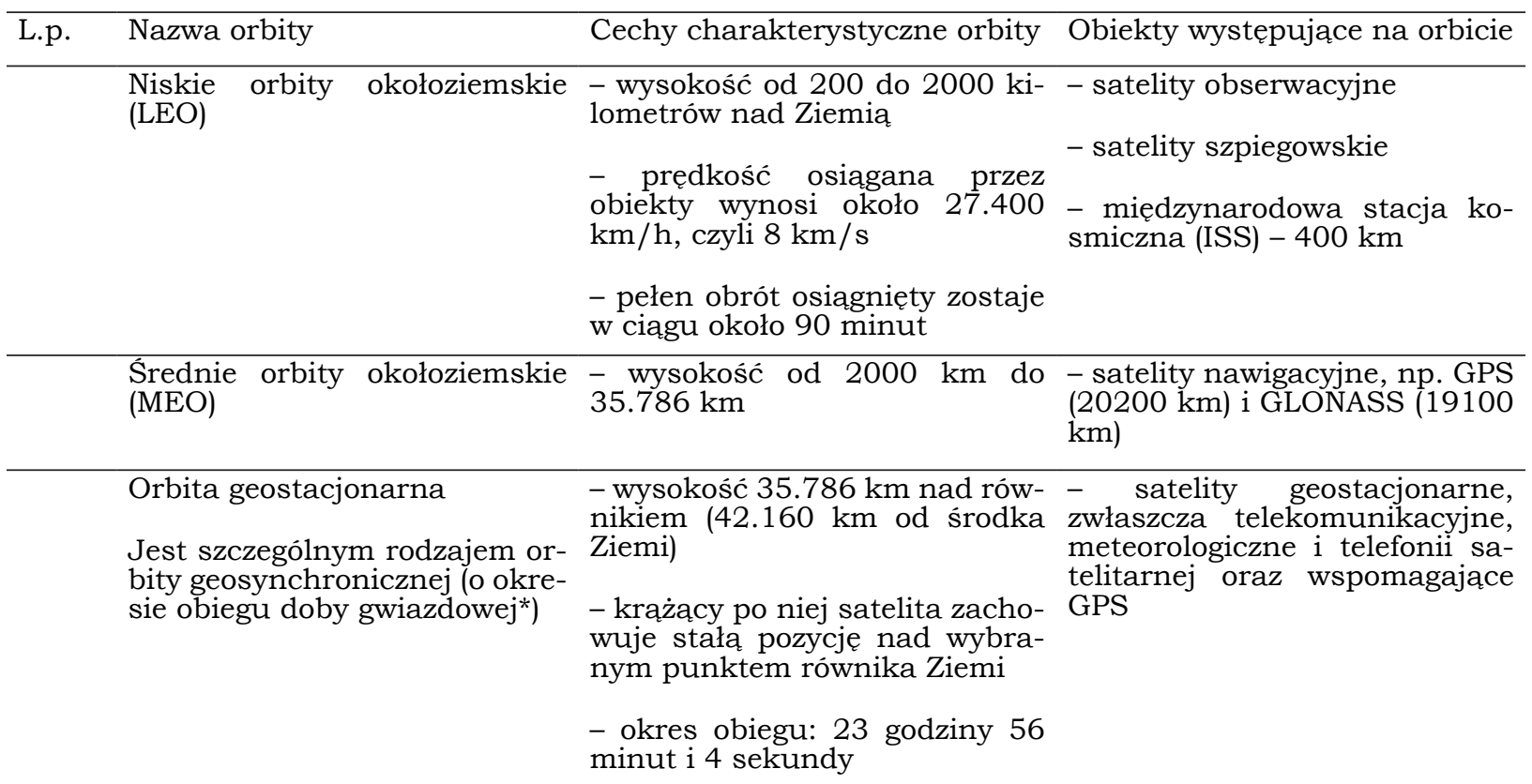

*doba gwiazdowa dzieli się na 24 godziny gwiazdowe (RYBKA 1978). wg https://www.nasa.gov/audience/forstudents/5-8/features/orbit_feature_5-8.html. 
spotkać określenie tego typu odpadów jako „space debris". Jest to specyficzny typ odpadów wytworzonych przez człowieka, nieprzydatnych i znajdujacych się na orbicie okołoziemskiej. Masa odpadów kosmicznych może kształtować się od kilku gramów do wielu ton, a ich rozmiar, od kilku milimetrów do kilkudziesięciu metrów. Odpady te znajduja się od około 100 do ponad $36.000 \mathrm{~km}$ nad powierzchnia Ziemi (NASA 2013). Ryc. 1 obrazuje zagęszczenie odpadów znajdujacych się na orbitach ziemskich.

Odpady kosmiczne znajduja się w ruchu i zmieniaja swoje położenie krażac po orbitach okołoziemskich - torach ruchu. Teorie ruchu satelitów sa bardziej skomplikowane niż prawa Keplera, dlatego ruch ten jest jedynie w przybliżeniu opisany empirycznymi prawami Keplera. Satelita już po kilku dniach ruchu orbitalnego może znajdować się po drugiej stronie Ziemi, w stosunku do przewidywań wynikajacych $z$ praw Keplera tak daleko ich ruch może odbiegać od tego prostego przybliżenia.

Wokół Ziemi znajduje się kilka typów orbit, na których umieszczane sa obiekty. W Tabeli 1 przedstawiono klasyfikację poszczególnych orbit okołoziemskich oraz rodzaje obiektów na nich umieszczanych. Na każdej $z$ orbit znajduja się różne rodzaje satelitów, które moga być źródłem kosmicznych odpadów. Obiekty krążące na wyższych orbitach, mimo zmniejszonego oddziaływania atmosfery, moga być wrażliwe na wpływ ciśnienia wiatru słonecznego czy oddziaływanie Księżyca.

\section{METODY POZYSKIWANIA INFORMACJI O ODPADACH KOSMICZNYCH}

Wiedza i informacje o odpadach kosmicznych moga być poszerzane przez analizę obiektów przebywających na orbicie. Śledzenie naziemne odpadów, ich identyfikacja i określanie ich populacji oraz katalogowanie jest możliwe za pomoca odpowiednich metod. Do monitorowania "space derbis", podobnie jak do innych obiektów, stosuje się techniki obserwacyjne i pomiarowe. Należa do nich techniki radarowe, które pozwalaja na określenie prędkości i odległości danego obiektu oraz jego położenie w sferze niebieskiej. Obiekty poruszające się na wyższych orbitach okołoziemskich moga być obserwowane jedynie przy użyciu teleskopów EU. Projekt SST (ang. Space Surveillance and Tracking Framework Support, Decision of 16 April 2014, No 541/2014/EU of the European Parliament and of the Council), to inicjatywa dotyczaca Europejskiego systemu wykrywania i śledzenia obiektów w przestrzeni kosmicznej (EUROPEJSKI SYSTEM

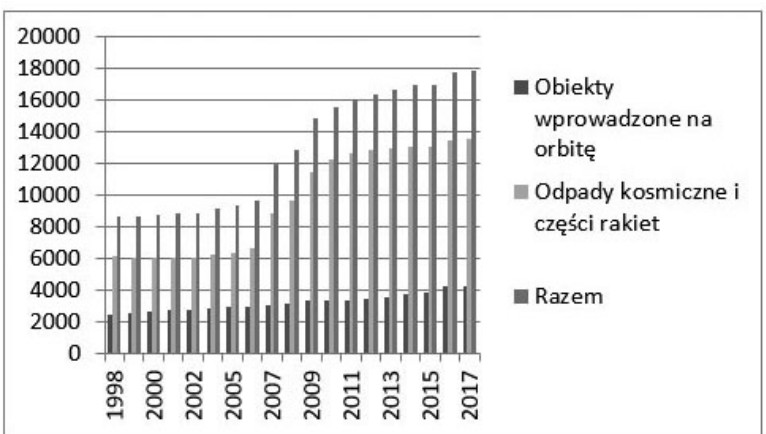

Ryc. 2. Ogólna liczba obiektów wprowadzonych na orbity oraz odpadów kosmicznych na orbitach okołoziemskich w latach 1998-2017 (Źródło: NASA https://www.orbitaldebris.jsc.nasa.gov/quarterly-news/newsletter.html).

2014). Jej celem jest ochrona satelitów europejskich przed niebezpieczeństwem kolizji $z$ innymi obiektami. W szczególności dotyczy ona problemu odpadów kosmicznych. Aby wzmocnić działania w tym obszarze, państwa europejskie: Francja, Niemcy, Włochy, Wielka Brytania i Hiszpania zawiazały konsorcjum SST w 2015 r.

Jedynym krajem utrzymujacym obecnie publicznie dostępny katalog obiektów satelitarnych (US Space Catalog, USSC) sa Stany Zjednoczone. W katalogu zarejestrowane sa wszystkie obiekty wytworzone przez człowieka i umieszczane na orbitach okołoziemskich od 1957 r. Znajdują się tam szczegółowe informacje zarówno o obiektach pozostajacych na orbitach, jak i o tych, które powróciły do atmosfery ziemskiej, albo wylądowały na ciałach niebieskich. Uproszczone i streszczone informacje publikowane sa przez Narodowa Agencję Aeronautyki i Przestrzeni Kosmicznej (ang. National Aeronautics and Space Administration, NASA) w sprawozdaniach kwartalnych o kosmicznych odpadach (NASA NEWS).

Źródłem informacji o kosmicznych odpadach moga być sprowadzone na ziemię satelity, np. satelita EURECA umieszczony na orbicie przez STS-46 i sprowadzony na Ziemię przez STS-57 oraz panele słoneczne teleskopu Hubbla ściagnięte przez misje STS-61 oraz STS-109 (STS to misje prowadzone $z$ użyciem wahadłowców kosmicznych; ang. Space Transportation System).

\section{ANALIZA ILOŚCI KOSMICZNYCH ODPADÓW NA ORBITACH OKOEOZIEMSKICH}

Przedstawione poniżej statystyki dotyczą tylko obiektów o rozmiarach co najmniej ok. $10 \mathrm{~cm}$. Istnieją setki tysięcy obiektów o rozmiarach od 1 do $10 \mathrm{~cm}$, które nie sa regu- 
larnie monitorowane, stanowiąc również poważne zagrożenie.

W Tabeli 2 i na Ryc. 2 przedstawiono liczbę obiektów znajdujących się na orbitach okołoziemskich w latach 1998-2017, z wyłączeniem 2003 r., dla którego brak jest danych. Wzięte zostały pod uwage zarówno obiekty wprowadzone na orbitę w poszczególnych latach, jak i odpady kosmiczne i części rakiet. Dane $z$ lat 1998-2013 dotycza stanu na czerwiec, dane $z$ lat 2014-2016 na lipiec, a dane z 2017 r. na styczeń. Analizując liczbę wszystkich obiektów znajdujacych się na orbitach okołoziemskich w badanym czasie można zauważyć, że przez analizowany okres przybyło aż 9227 obiektów. W szczególności przybywa odpadów kosmicznych, które w 1998 r. występowały w liczbie 6150, a w 2017 r. ich liczba wyniosła już 13573. Zatem w latach 1998-2017 przybyło aż 7423 nowych odpadów kosmicznych. Oznacza to wzrost o $120,7 \%$ porównując liczebmość odpadów w roku 1998 z rokiem 2017. Dane $Z$ analizowanego okresu (z wyłączeniem roku 2003) obrazuja problem wciąż rosnącej liczby odpadów kosmicznych.

Tabela 2. Ogólna liczba obiektów wprowadzonych na orbity oraz odpadów kosmicznych na orbitach okołoziemskich w latach 1998-2017.

\begin{tabular}{|c|c|c|c|}
\hline Rok & $\begin{array}{c}\text { Obiekty wpro- } \\
\text { wadzone na } \\
\text { orbitę }\end{array}$ & $\begin{array}{c}\text { Odpady } \\
\text { kosmiczne i } \\
\text { części rakiet }\end{array}$ & Razem \\
\hline 1998 & 2499 & 6150 & 8649 \\
\hline 1999 & 2610 & 6085 & 8695 \\
\hline 2000 & 2675 & 6092 & 8767 \\
\hline 2001 & 2732 & 6099 & 8831 \\
\hline 2002 & 2784 & 6087 & 8871 \\
\hline 2003 & b. $d$ & b. d. & b. d. \\
\hline 2004 & 2897 & 6251 & 9148 \\
\hline 2005 & 2944 & 6408 & 9352 \\
\hline 2006 & 3000 & 6680 & 9680 \\
\hline 2007 & 3095 & 8859 & 11954 \\
\hline 2008 & 3163 & 9688 & 12851 \\
\hline 2009 & 3371 & 11492 & 14863 \\
\hline 2010 & 3333 & 12217 & 15550 \\
\hline 2011 & 3396 & 12698 & 16094 \\
\hline 2012 & 3499 & 12900 & 16399 \\
\hline 2013 & 3612 & 12990 & 16602 \\
\hline 2014 & 3812 & 13088 & 16900 \\
\hline 2015 & 3917 & 13008 & 16925 \\
\hline 2016 & 4242 & 13487 & 17729 \\
\hline 2017 & 4303 & 13573 & 17876 \\
\hline
\end{tabular}

Obserwowane skokowe wzrosty tej liczby w latach 2007 i 2009 wywołane były dwoma wydarzeniami: zestrzeleniem chińskiego satelity Fengyun oraz zderzeniem satelitów Irydium 33 i Kosmos 2251.

Całkowita liczba wszystkich obiektów krążących na orbitach okołoziemskich wynosiła w styczniu 2017 r. 17876, w tym znajdują się 4303 czynne satelity, a nieczynne obiekty, które kwalifikowane jako odpady występuja aż w liczbie 13573. Wynika z tego, że odpadów jest ponadtrzykrotnie więcej niż czynnych obiektów. Daje to obraz ilości bezużytecznych obiektów w przestrzeni kosmicznej i jest sygnałem, że tendencja ich przyrostu będzie się utrzymywać. Należy zwrócić uwagę, że pracujace obecnie satelity maja określony czas żywotności, po którym dołączą do grupy kosmicznych odpadów, a więc liczba odpadów w przestrzeni kosmicznej będzie sukcesywnie wzrastać.

Analizowane dane liczbowe zostały zaczerpnięte $z$ bazy katalogowanej przez U.S Space Surveillance Network.

\section{PRÓBY MINIMALIZACJI ODPADÓW KOSMICZNYCH}

Problem wzrastającej liczby odpadów kosmicznych skłonił organizacje i instytucje, a także państwa zaangażowane w rozwój przemysłu kosmicznego, do prób podjęcia odpowiednich działań w celu poszukiwań optymalnych rozwiązań. Jednak wciąż jest wiele trudności w znalezieniu i wdrożeniu efektywnych metod minimalizujących ilość odpadów kosmicznych.

Najbardziej kłopotliwe odpady orbitalne to: nieczynne satelity, górne człony rakiet nośnych i części obiektów. Zagrożenia ze strony odpadów głównie dotycza innych obiektów poruszajacych się po orbitach. Do głównych metod zmniejszajacych niebezpieczeństwo kolizji zaliczane sa odpowiednie manewry orbitalne. Polegaja one na właściwej korekcie orbity przez operatorów działajacych satelitów w celu zmniejszenia ryzyka zderzeń. NASA pracuje nad programem minimalizacji odpadów (ang. Space Debris Mitigation Programme). Powołany został również Międzyagencyjny Komitet Koordynacyjny ds. Odpadów Kosmicznych (ang. The Inter-Agency Space Debris Coordination Committee, IADC), działajacy na zasadach międzynarodowego forum, skupiajacego rzacdowe organizacje w celu koordynacji działań zwiazanych z kwestiami odpadów w przestrzeni kosmicznej pochodzenia naturalnego oraz wytworzonych przez człowieka. Organizacja ta ma na celu wymianę informacji na temat odpadów i współpracę w zakresie badań naukowych w tym obszarze. 
Europejska Agencja Kosmiczna (ang. European Space Agency, ESA) dąży do osiągnięcia „czystej przestrzeni” (ang. clean space), wprowadzając szereg działań i programów. Do tego przedsięwzięcia niezbędne sa regulacje prawne. Przykładami takich uregulowań moga być te już wdrożone: Rozporządzenie UE $z$ dnia 18 grudnia 2006 r. (ROZPORZÅDZENIE 2006) dotyczace rejestracji, oceny, autoryzacji i ograniczania użycia chemikaliów [ang. Regulation of the European Parliament and of the Council concerning the Registration, Evaluation, Authorisation and Restriction of Chemicals (REACH) (EC $1907 / 2006)]$ i Dyrektywa z dnia 27 stycznia 2003 roku (DYREKTYWA 2003), dotyczaca zmniejszenia ilości substancji niebezpiecznych [ang. Restriction of Hazardous Substances Directive (2002/95/EC)].

W dażeniach do osiagnięcia czystej przestrzeni kosmicznej duże znaczenie maja konkurencyjne, przyjazne środowisku technologie, określane jako „zielone technologie” (zmniejszające zużycie surowców, materiałów, zwiększajace recykling i wykorzystanie odpadów, efektywność energetyczna, stosujace zintegrowane układy procesowe itp.). Ważny jest także rozwój sektora kosmicznego oraz korzystanie $\mathrm{z}$ przestrzeni kosmicznej $\mathrm{w}$ sposób zrównoważony. Zatem, w inicjatywie „czysta przestrzeń” wyzwania dotycza działań zarówno odbywajacych się w przestrzeni kosmicznej, jak i na Ziemi. Działania te rozpoczynaja się od ekoprojektowania, które również pozwoli na ocenę wpływu na środowisko i monitoring ryzyka legislacyjnego. Ponadto, zmienia się również postępowanie $z$ nowo wypuszczanymi w przestrzeń kosmiczna obiektami, które będą posiadały program wytycznych postępowania $z$ nimi po zakończonej misji.

System, który ESA zamierza wykorzystywać, nosi nazwę Aktywny System Usuwania Odpadów (ang. Active Debris Removal, ADR) i ma za zadanie stabilizację ilości „space derbis" w przestrzeni kosmicznej. Polega on między innymi na deorbitacji kosmicznych odpadów. Deorbitacja to manewr sprowadzenia obiektu kosmicznego $z$ orbity w gęste warstwy atmosfery, gdzie uległby on spaleniu. Deorbitacja wiąże się niestety $z$ bardzo dużymi nakładami finansowymi i jest nieefektywna. Satelity sprzatajace kosmiczne odpady moga doprowadzić do deorbitacji zaledwie od jednego do kilku odpadów kosmicznych. To bardzo niewiele, biorac pod uwage liczbę odpadów liczona w tysiącach. Kolejnym ogniwem w dążeniu do czystej przestrzeni jest wdrożenie technologii ograniczania odpadów w przestrzeni kosmicznej (ang. Space Derbis Mitigation) oraz korygo- wanie ilości odpadów w przestrzeni kosmicznej (ang. Space Derbis Remediation).

\section{PODSUMOWANIE}

Problem odpadów kosmicznych generowanych przez człowieka wymaga kompleksowych rozwiązań. Przestrzeń orbitalna wokół Ziemi jest coraz bardziej zatłoczona przez krażące po orbitach nieczynne satelity, nieprzydatne elementy rakiet $i$ inne kosmiczne odpady, będace wytworem działalności ludzkiej. Stanowia one zagrożenie dla innych obiektów przebywających na orbitach okołoziemskich. Szczególnie zatłoczona jest orbita położna najbliżej ziemskiej atmosfery, tzw. niska orbita okołoziemska (ang. Low Earth Orbit, LEO). Instytucje i państwa zajmujace się eksploracja kosmosu szukaja rozwiązań ograniczających zagrożenia ze strony kosmicznych odpadów i zmniejszajacych ich ilość na orbitach. Metody te sa kompleksowe i wymagaja dużych nakładów finansowych i działań w wielu obszarach. Europejska Agencja Kosmiczna (ESA) kładzie nacisk na rozwój inicjatywy „czystej przestrzeni”, która ma na celu zmianę podejścia do użytkowania przestrzeni kosmicznej. Sektor kosmiczny czeka wiele wyzwań, które wiąza się $z$ wdrażaniem technologii i metod realizujących założenia „czystej przestrzeni” $z$ jak najmniejszym negatywnym oddziaływaniem na środowisko naturalne zarówno na Ziemi, jak i w przestrzeni orbitalnej. Do takich narzędzi można zaliczyć tzw. „zielone technologie", ekoprojektowanie, oceny oddziaływania na środowisko, zmiany legislacyjne, programy służące deorbitacji i ograniczania odpadów kosmicznych.

Streszczenie

Odpady kosmiczne wytworzone przez człowieka stanowia istotny problem $\mathrm{w}$ przestrzeni kosmicznej. Niepokojąca jest wciąż wzrastająca liczba tego typu obiektów na orbitach okołoziemskich. Odpady te krażą obok czynnych obiektów, głównie sztucznych satelitów Ziemi, umieszczanych na orbitach $\mathrm{w}$ różnych celach, które po pewnym czasie staja się także zbędne, zasilając populacje kosmicznych śmieci. Obserwowany wzrost liczby bezużytecznych obiektów wiaże się przede wszystkim $z$ niebezpieczeństwem kolizji w przestrzeni kosmicznej. Dlatego problem ten wymaga odpowiednich rozwiazzań i działań ze strony środowiska naukowego i instytucji zajmujacych się eksploracja kosmosu. W pracy przeanalizowano kształtująca się ilość i rodzaje odpadów kosmicznych oraz źródła ich pochodzenia $w$ ostatnich dziesięcioleciach. Ponadto określono miejsca ich występowania oraz zagrożenia jakie moga powodować, a także określono próby minimalizacji liczby odpadów tego typu.

\section{LITERATURA}

DYREKTYWA, 2003. Dyrektywa $z$ dnia 27 stycznia 2003 roku, dotyczaca zmniejszenia ilości sub- 
stancji niebezpiecznych - Restriction of Hazardous Substances Directive (2002/95/EC).

EUROPEJSKI SYSTEM, 2014. Europejski system wykrywania $i$ śledzenia obiektów satelitarnych - Space Surveillance and Tracking Framework Support. Decision of 16 April 2014, No 541/2014/EU of the European Parliament and of the Council.

NASA (National Aeronautics and Space Administration), 2013. Space debris and human spacecraft. https://www.nasa.gov/mission pages/station/news/orbital_debris.html.

NASA News (National Aeronautics and Space Administration). U. S Space Surveillance Network, Orbital Debris Quarterly News, 3
(1998) - 21(2017) https://www.orbitaldebris. jsc.nasa.gov/quarterly-news/newsletter.html.

ROZPORZĄDZENIE, 2006. Rozporzadzenie UE $z$ dnia 18 grudnia 2006 r. dotyczace rejestracji, oceny, autoryzacji $i$ ograniczania użycia chemikaliow. Regulation of the European Parliament and of the Council concerning the Registration, Evaluation, Authorisation and Restriction of Chemicals (REACH) (EC 1907/2006).

RYBKA E., 1978. Astronomia ogólna. PWN, Warszawa.

KOSMOS Vol. 67, 2, 449-454, 2018

\section{JUSTYNA MUWEIS}

Department of Management in Power Engineering, Faculty of Management, AGH University of Science and Technology,

10 Gramatyka Str., 30-067 Krakow, E-mail: jmuweis@zarz.agh.edu.pl

\section{SPACE DEBRIS AND THE ATTEMPT OF THEIR MINIMALIZATION}

\section{Summary}

Space debris produced by man pose significant problems in near Earth space. Disturbing is still increasing amount of this type of waste. The wastes circulate alongside the working objects - mainly the Earth artificial satellites placed in orbit for a variety of purposes, which after some time become also useless supporting the space debris population. The observed increase in the number of useless objects is associated primarily with the danger of a collision in space. Therefore, this problem requires appropriate solutions and actions from the scientific community and institutions dealing with space exploration. The work analyses the number and types of waste shaping the space and their origin in recent decades. In addition, there are specified places of their occurrence, risks that they may cause, and also attempts to minimize this type of waste.

Key words: artificial satellites, deorbitation, risk of collision, space debris 